\title{
ROUPNEL E BACHELARD: DEVANEIOS E ESPACIALIDADES GEOPOÉTICAS ${ }^{1}$
}

\author{
Gabriel Kafure da Rocha (UFRN) ${ }^{2}$ \\ gkafure@gmail.com
}

Resumo: A presente investigação pretende defender a ideia, como homenagem após os 60 anos da morte de Gaston Roupnel (1871-1946), de que há uma influência que vai além da noção de Instante como descontinuidade sobre Bachelard (1884-1962). Por essa via, a virada da filosofia bachelardiana para a crítica literária e poética perpassa uma cosmovisão influênciada por Roupnel em Siloë (obra muito rara, geralmente citada indiretamente e ainda não traduzida para o português). Ao ter acesso direto a esse texto percebe-se que ali se dá um recomeço, uma nova ontogênese da vida para a ideia de devaneios espaciais de uma perspectiva que une duração e instante, espaço e tempo. Nesse sentido, pretendemos desvelar a influência roupneliana sobre Bachelard por fora de A intuicão do instante, no intuito de demonstrar a hipótese que foi a partir de Siloë que se abre o espaço para o devaneio bachelardiano.

Palavras-chave: geopoética; espaço; tempo; energia.

\footnotetext{
${ }^{1}$ Recebido: 16-07-2017/Aceito: 01-10-2017/ Publicado on-line: 12/04/2020.

${ }^{2}$ Gabriel Kafure da Rocha é Doutorando em Filosofia pela Universidade Federal Rio Grande do Norte, Natal, RN. Brasil.
} 


\section{CONSIDERAÇÕES INICIAIS}

"O homem é um deus quando sonha e não passa de um mendigo quando pensa"

Hölderlin

Publicado em 1927, Siloë é um livro raro, citado por muitos pesquisadores, foi pouco lido integralmente. Por isso, há um certo misticismo envolto na ideia do conteúdo desse livro, o que realmente condiz de certa forma com o aspecto poético dele. Bachelard, em 1927 publicou sua primeira tese, dividida em duas partes, Étude sur l'évolution d'un problème de physique além do Essai sur la conaissance approchée e em 1932 publica L'intuition de l'instant, onde cita diretamente a leitura de Siloë. Contudo, interpretando o texto $\mathrm{O}$ mundo como capricho e miniatura temos uma nova pista de elementos da influência poética de Roupnel sobre Bachelard. Pretendemos assim, fazer uma revisita noturna dessas leituras e criar uma hipótese que sobrepassa a visão mais usual sobre a relação entre ambos filósofos.

A amizade de Bachelard com Roupnel ${ }^{3}$ se inicia quando se tornam colegas na faculdade de letras e história de Dijon. Quando Roupnel publica Histoire de la campagne française (1927) se torna famoso por representar a cultura

\footnotetext{
${ }^{3}$ Roupnel (Louis Gaston Félicien) : né le 23 septembre 1 871, il étudie l'histoire à Dijon puis à la Sorbonne sans parvenir à passer l'agrégation. Il acquièrt sa notoriété d'écrivain régionaliste en publiant Nono, roman qui manque de peu le prix Goncourt en 1910. Il soutient sa thèse sur La Ville et la Campagne dijonnaise au XVII' siècle en 1922 et obtient une chaire à l'université de Dijon, où il se lie d'amitié avec Bachelard qui s'inspirera de l'une de ses œuvres poétiques, Siloë (1927), pour critiquer la conception du temps continu de Bergson. Son Histoire de la campagne française ( 1932) obtient un prix de l'Académie Française et retient aussi l'attention de Marc Bloch." (BONTEMPS 2010, p. 230)
} 
popular camponesa. Segundo Bachelard, Roupnel tinha uma capacidade de ouvir as verdades interiores dos camponeses e que isso se caracterizou uma influência importante para a escola da imaginação poética bachelardiana. "Cada indivíduo recapitula a sua história total. Para Roupnel, a transcendência é o fenômeno da própria consciência." (PARINAUD 1996, p. 79). Desse modo, o local, região e cultura em que cada um constrói sua subjetividade é fundamental para entender o fenômeno da vida. Por essa via, no mesmo ano de 1927, ao publicar Siloë, a obra chama a atenção de Bachelard por tratar de uma metafísica que alia biologia com a mecânica ondulatória.

Eu não sei pensar que as coisas do meu país. Eu sei vivê-las, como Gaston Roupnel o amigo inesquecível que me ensinou, a dialética de extensões rurais e das áreas arborizadas. No vasto mundo do não Eu, o não Eu dos campos não é o mesmo que o não Eu das florestas! (BACHELARD 1993, p. 214).

Nessa dialética de entendimentos campesinos, compreender o passado pelo presente e não o presente pelo passado, essa é a premissa que Siloë traz como um livro basicamente composto de duas partes, Bios e Nous, nos interessamos aqui especialmente pela segunda parte, visto que, na primeira parte, Roupnel estabelece sua ontogênese biológica baseada na tese de que a natureza está eternamente recomeçando. "Gaston Roupnel vê em cada átomo o centro do universo inteiro e que abrange, pela variedade de combinações, valor da novidade permanente." (PARINAUD 1996, p. 79). 


\section{ROUPNEL E SILOË}

Roupnel também entende que a energia é a memória, nesse sentido a vida que eternamente recomeça se manifestando enquanto Nous, é a inteligência que memoriza a vida, o espírito em manifestação da consciência universal. Ele começa a explicar justamente a importância do entendimento do tempo e do espaço como uníssono ao instantevida, a unidade espiritual que anima toda a natureza.

Logo, nessa concepção, o espaço deve ser entendido como continuidade e duração, condição para o ritmo harmônico do ser como uma unidade funcional. Na medida que o espaço tem sua estrutura atômica desvelada em pontos, o tempo se desvela por instantes. Assim, há um pontovida que traduz as "silhuetas deformadas de uma realidade comum" (ROUPNEL 1927, p. 123)

Roupnel entende que o espaço e tempo são propriedades atômicas responsáveis pela evolução da vida, e entre o universo e o átomo existe uma espécie de dinamismo na qual a velocidade da vida realiza a existência objetiva da luz, energia, memória.

Nisso, a natureza preenche o espaço do mundo vivo ressonante da vida, criando silêncios e vazios. A consciência se põe em ressonância com todas as vozes do universo, mas como isso se dá?

Isto não é somente sobre os campos do espaço que nossa consciência faz sua colheita de erros. Ela escolheu toda a superfície enorme do tempo que as obras de um momento e os frutos de um momento. Assim como nossa consciência suporta apenas o momento presente, da mesma forma, o funcionamento do nosso ser, ela não se importa com a sensação entrelaçada naquele momento. Como nosso eu, nos- 
sa consciência não é composta apenas de imediatismo. Ela solta sua percepção da sensação que atravessa em vários instantes (ROUPNEL 1927, p. 135).

A consciência é um acumulado de sensações que tece relações com o exterior na medida que toma consciência do ser é intermediária entre o átomo e o universo. Esse é o gênio da alma, enquanto quer explorar o espaço infinito. É aí também que o pensamento se manifesta como expressão da realização das vozes do ser,

A antiga fronteira entre matéria e espírito, substância e energia, foi há muito tempo abolida. Negando todas essas classificações, que mutilaram para nós a melhor abordagem de nossas ignorâncias, a natureza estende-se durante todo o reinado de sua unidade de energia. (ROUPNEL 1927, p. 143).

Roupnel pretende construir um novo rerum natura, em que a natureza do ser como consciência universal que em suas simetrias e proporções são entendidas como a luz do espaço. Eis que essa é a expressão das reciprocidades, não entre expansões particulares, mas a combinação em harmonia entre a forma e o sentido da vida. Roupnel parece realizar um salto, por meio da ideia do instante, da ciência biológica para um panenteísmo fundamentado no amor. Contudo, tal salto não é uma fuga da fundamentação, mas sim uma justificativa de que a energia superior da natureza é o amor e é por meio dessa força que a luz e a consciência dão sentido a um mundo inacabado e que recomeça eternamente.

Contudo, ainda assim essa relação entre consciência e natureza é explicitada como uma própria criação nossa, nesse sentido, Roupnel dá um passo à frente dos dogmatismos 
da relação entre espiritualidade e ciência, assumindo que

Deus é assim construído por nós mesmos. É feito de pura espiritualidade. Sua realização é confusa em sua revelação. Também é ilógico que ele deseja discar uma realidade, objetiva e independente, para tentar construir um espaço objetivo e uma duração independente (ROUPNEL 1927, p. 173).

Cada alma tem seu deus enquanto expressão do ser universal, é aí que nasce a abertura para o devaneio, na medida em que Deus é "o sonho livre de nossas almas, a elevação superior de nosso pensamento" (ROUPNEL 1927, p. 173), ou seja, o devaneio enquanto sonho e imaginação é a manifestação do que há de mais divino no ser humano. É ali que ele se liga a ideia de que podemos ser sonhos de um deus e sonhamos porque somos deuses aprendendo a lidar com o nosso universo que criamos internamente. Roupnel joga o tempo todo com esses aspectos entre macro e micro, mundos internos e externos, tal como Bachelard empreende na dialética do interior e exterior de A poética do espaço.

Eis os dias de sua infância e seus sonhos puros!... Este é o horizonte de sonho e Siloë aqui!... Oásis de felicidade! .. Terra dos sonhos, onde o ar é abençoado!... Mas então, onde que Siloé está no tempo?... Siloé que ressuscita ao dia mais doce?... (ROUPNEL 1927, p. 187).

É aí que no capitulo quarto da segunda parte ele explicita a ideia do que representa Siloë; a de que nossos pensamentos percorrem o espaço no destino de gestos realizados, somos pensamento e a duração que damos a eles é o segredo da fonte da vida e da juventude, "Contra a cegueira da ignorância imersa no mundo da temporalidade, 
indica-se a luz do conhecimento abençoada pelas águas de Siloé." (MOVSCHOWITZ 1993, 97)

É onde nosso cérebro aprende a lidar com o tempo e aceitar essa ligação inerente com o universo. Roupnel parece admitir ideias como pecado e mal, contudo, sua maturidade entende que a complementariedade do bem e mal se transforma no instante da descontinuidade. O pensamento gera ação e suas consequências devem quebrar o eterno ciclo do bem e mal, para isso é preciso entender com serenidade a possibilidade dos eternos recomeços do universo e aceitar a duração do bem e abandonar o mal enquanto vida-morte.

\section{BACHELARD E O MUNDO}

Publicado entre 1933-1934, um ano após A intuição do instante, o artigo $\mathrm{O}$ mundo como capricho e miniatura foi escrito por Bachelard. Parinaud (1996) sugere que em tal texto se evidencia a influência roupneliana sobre um Bachelard ainda epistemológico que se abre ao poético. Em tal artigo, não há nenhuma citação direta à Roupnel, contudo, o fato de ter sido escrito logo após as Intuições atomísticas nos fornece uma pista importante sobre como Bachelard estava alinhado com Siloë e as funções intuitivas entre átomo, instante, espaço e mundo.

É muito belo o início do texto quando Bachelard evoca o azul do mundo como um planeta água "no tênue desenho do meu devaneio, no limiar do meu pensamento!" (BACHELARD 2008, p. 23), é interessante lembrar que a dicotomia entre sujeito/objeto tem na separação entre ser/mundo uma de suas raízes originárias. Nesse sentido, o 
próprio Bachelard relembra na representação que "é preciso quebrar a imagem que eu contemplava quando ele [o mundo] era uno" (BACHELARD 2008, p. 23 - grifos nossos).

Esse é o longo trabalho que o espírito e a matéria parecem fazer por se auto conhecer em cortes epistemológicos ou auto criar o universo como Roupnel almejava em Siloë. $O$ mundo precisa repousar sobre o punctum remoto do devaneio, ou seja, na espacialidade que o ponto desvela onde o mundo se dissolve ou se recria.

Gagey (1969) relembra que o devaneio, de certa forma, arruína o mundo, assim como o trabalho e a razão também. O mundo de imagens tem valores próprios, delimitados pela capacidade de nossa linguagem de descrever a totalidade dos entes que compõe a realidade de um povo. Bachelard nos convida a um panorama que dá unidade ao mundo como totalidade, na vontade de encontrar a ação de ordenar os valores objetivos para reintegrar a essa miniatura do mundo.

A representação é a organização da memória, "o lugar exato em que o movimento da consciência muda de sentido para retornar do eu para o Mundo." (BACHELARD 2008, p. 25). A representação é a localização visual do impalpável, é nesse mundo em que o eu e o objeto repousa no mínimo, na intuição de um sujeito num caleidoscópio distante. A representação é fazer do mundo um brinquedo com impulsos próprios, "da miniatura iremos, portanto, para as coisas" (BACHELARD 2008, p. 27), ou seja, saímos do campo do objeto que vem contra e vamos ao encontro das coisas e de como a consciência às representa. No movimento de encontro às coisas, saímos dos caprichos às forças, encontrando a matéria ou a energia que Roupnel encarava como 
memória de instantes-vida.

Essa é uma passagem da inversão entre a visão objetiva e o devaneio visual, na inutilidade homográfica entre objeto e sensação e consequentemente a disfunção entre a imagem e a sensação observada e reconhecida nos impulsos e intensidades.

O germe da representação é o ponto de fixação onde "um ponto imaginário [é] situado no centro de um devaneio ou de uma lembrança. As coisas aparecem primeiro onde as procuramos, e só lentamente as colocamos onde elas estão." (BACHELARD 2008, p. 30).

Bachelard parece ter encontrado no mundo a representação atômica de uma imagem que relaciona o espacial com a energia e a prospecção. Por prospecção, Bachelard entende a ideia do simulacro, uma imitação mais completa quanto possível do que causa um sobressalto da consciência na capacidade de localizar as sensações do imaginário. "A vantagem da experiência pelas imagens consecutivas está em permitir que se decomponha no tempo o complexo excitação-sensação" (BACHELARD 2008, p. 31).

A representação procede à miniatura do mundo, dando justamente a sensação das cores que emergem do devaneio, numa viagem entre os objetos e o eixo da visão. Bachelard evidencia aí uma leitura profunda e minuciosa.

Ainda que um mundo eduque os sentidos do observador, ao atribuir quatro e não três dimensões ao espaço visual completo, ele deve questionar o pretexto dessas quatro dimensões num desenvolvimento de objetivação espacial por meio dos conceitos de profundidade e aprofundamento. É o aprofundamento que abre para a quarta dimensão 
em que

[...] passado o limiar metafísico, é uma dimensão infinita para a qual só se podem conceber limites para qualquer outra dimensão. No interior do ponto simbólico das três dimensões cartesianas abre-se então uma perspectiva interna. Todo objeto tem uma extensão interna que se acrescenta à extensão externa. (BACHELARD 2008, p. 37).

Por fim, Bachelard sugere que a intensidade equivale também a uma dimensão, é onde se "prova que o conhecimento energético do espaço é conhecido igualmente por uma ordenação de esforços" (BACHELARD 2008, p. 37). Logo, um espaço de três dimensões é o contentamento com um complexo onde a gravidade varia pouco e as dimensões também não tem um intercâmbio ativo. É a quarta dimensão que possibilita a troca, com as intensidades dos espaços sólidos e abstratos, miniaturas e figuras geométricas, é nesse espaço que incorpora uma relatividade da temporalidade que o imaginário se permite a ser essa ponto-vida que cria o universo pela percepção do mundo.

A dimensão do aprofundamento permite saber que a não visualidade da interioridade delineie a compreensão dos anáglifos, ilusões de um plano bidimensional que simulam a terceira dimensão. É retomando a retina, à essência

\footnotetext{
4 “É nesse mesmo espaço. Não há outro espaço que não seja o ponto-vida que é a presença de vida. Repletos dessa percepção ampliamos a plenitude da existência, nós preenchemos tudo o que não é nosso. Assim, fazemos um espaço exterior. Certamente, nessa construção, a experiência nos defende em todos os lugares pela intensidade da vida; mas nosso espírito previne o hábito ao redor de todo local; e nossa área exterior consiste em pontos-vida dos quais a maioria é ainda não atribuída. E como não podemos imaginar que há um espaço em branco entre estas construções parciais de pontos, aplicamos um contato imediato que os constitui nessa continuidade, nessa geometria que nos dá os números em forma de linhas, superfícies e volumes." (ROUPNEL 1927, p. 122).
} 
do olhar, que o espírito prepara um mundo de construções abstratas, mas é no devaneio que saboreia o fruto proibido das alucinações.

\section{UMA VISÃO GEOPOÉTICA}

A partir da perspectiva apresentada, podemos tentar sintetizar a relação entre Roupnel e Bachelard pelo prisma contemporâneo da geopoética. Assim num livro recentemente lançado por importante comentador de Bachelard, Jean-Jacques Wunenburger, Os espaços geopoéticos (2016) retoma a geopoética que se colocou como um conjunto de saberes que avança no movimento acadêmico divulgado por Kenneth White. O autor empreende o que pretendemos expressar no presente artigo, tanto pela inspiração roupneliana, como pelas passagens bachelardianas, o entendimento de que na medida que a geopoética pode ser englobada como uma reflexão sobre a natureza, ela incorpora boa parte do pensamento espacial na história da filosofia, e nisso Roupnel e Bachelard tem um grande valor. Ainda sobre essa história, Kenneth White irá dizer,

Como um refugiado da ciência, Bachelard é mais indulgente à poesia que é com a filosofia (e, diga-se, muito a um poeta). Onde o filósofo está à procura de ser (e na maioria das poesias iria encontrar uma única fantasia e psicologia), o cientista, tentando livrar-se de um racionalismo redutor, é menos radical e têm prazer em encontrar-se em uma atmosfera de intimidade sensível, repleta de ambiguidade (WHITE 1992, p. 171)

Nesse sentido, nos parece que White está em conso- 
nância com a continuidade ou ruptura que há entre os dois filósofos, tais leituras parecem inspiradoras, visto que a geopoética pretende estabelecer uma relação sensível e inteligente de habitar a terra. Segundo a Profa Rachel Bouvet, também estudiosa da geopoética, isso implica literalmente numa pesquisa de campo, em que,

Importa, em geopoética, atravessar diferentes territórios geográficos e culturais. Em seus ensaios, Kenneth White insiste na necessidade de sair, a fim de captar, graças à viagem, toda a beleza do mundo, que se encontra, dentre outras coisas, em sua diversidade, e de explorar, graças ao nomadismo intelectual, os diferentes saberes e as diferentes obras artísticas e literárias desenvolvidas nas mais diversas culturas. (BOUVET 2012, p. 13).

Nessa perspectiva, isso nos leva a questionar a aplicabilidade de toda essa perspectiva geopoética dentro de nossa cultura e entender a aplicabilidade dessa ontogênese de Roupnel e Bachelard. Ao vivenciar um pouco mais de culturas ligadas principalmente a língua francesa, é possível encontrar a dita topologia do ser em Bachelard e comparar, fazer analogias mais profundas com nossa visão de mundo. Ainda nessa perspectiva, ou mesmo na sua tensão, é talvez na geopoética que possam se estabelecer as fronteiras desses terrenos que vão desde o espaço abstrato até o espaço geográfico permeado pelo clima e a vegetação, ou seja, por uma eco-poética.

Nesse sentido, utilizaremos a seguir a visão geopoética

\footnotetext{
${ }^{5}$ Tal termo, apesar de ter sido cunhado por Heidegger, nos dá uma abertura para ser trabalhado também do ponto de vista bachelardiano por conta de conceitos desse último como a topoanálise e a topofilía.
} 
de Wunenburger (2016), importante pesquisador bachelardiano, que em L'imagination geopoïetique consegue equilibrar muito bem a história da espacialidade poética na filosofia, se valendo muito da teoria de Roupnel e Bachelard e por esse motivo, consistindo como uma importante referência para a visão meta-ontológica do espaço entre ambos os filósofos em foco.

Wunenburger relembra que a obra de Roupnel Histoire de la campagne française contém um teor geopoético na medida em que na espacialidade do campo, a natureza pode ser vista em eras e séculos antes reduzidos ao silencio, mas que a geopoética da alma ancestral do camponês revela a alma popular. "G. Roupnel encontra no campo francês o traço rural vivo dos recursos ou fontes que animam crenças imemoriais" (WUNENBURGER 2016, p. 183)

A alternância das zonas e culturas na vida camponesa francesa teria uma lógica econômica e mítica, nela não há nada de diferencial de um sentido agronômico. Entretanto, na medida em que a relação entre campo e natureza tivesse no trabalho um lugar de contato com a natureza, que seria, na visão de Wunenburger, as florestas, espaço da relação entre o profano e o sagrado, o cultural e o biológico existira a mesma possibilidade geopoética que qualquer lugar que o vasto mundo pode propiciar. "Onde a cultura retirou-se para abrir caminho para a efusão e a confusão com a Natureza. Como demonstrado por Gaston Roupnel em sua Histoire de la campagne française" (WUNENBURGER 2016, p. 106).

O importante pesquisador de Roupnel, Prof. Philip Whalen também parece concordar com essa visão roupneli- 
ana contemporânea, quando escreve o artigo intitulado La mise en lumière des travaux de Gaston Roupnel (1871-1946) en que de la "Préface" inédite de l'Histoire de la campagne française. Nesse trabalho, é possível acompanhar o percurso de um Roupnel Eco-místico, que tem como concepção metafísica os mundos ecológicos e espirituais, o que fica bem evidente em sua obra Siloë, visto que a sua primeira parte é uma ontogênese biológica. Segundo Whalen, metafisicamente é possível desvelar uma relação sintética entre preceitos holísticos de uma tradição monística, por isso, ele considera Roupnel um panenteísta, "Roupnel se esforçou para compreender a mentalidade camponesa em termos do que é inata, primitiva e consciência coletiva panenteísta que chamou de 'alma camponesa"' (WHALEN 2001, p. 90)

Voltando a relação entre Roupnel e Bachelard, fica evidente que o emprego de uma epistemologia não convencional que dá espaço as sensações corporais, percepções místicas e não discursivas foram influências importantes no estudo de uma dialética geopoética dos movimentos campesinos da época. Ao mesmo tempo, a importância de seu trabalho sócio-histórico teve ressonâncias com outros pensadores como Halbswachs, Cassirer.

Já Bachelard, do ponto de vista geopoética tem diversas interfaces, basicamente favorecidas por uma visão do espaço exterior como uma paisagem natural que favorece o entendimento de uma abertura cósmica na qual o interior é desvelados pelos espaços íntimos da casa num entrecruzamento simbólico e topológico. Assim como em Roupnel, é possível dizer que

Para Bachelard, somos todos psicologicamente mais ricos por po- 
dermos casar nossas imagens com as de uma percepção externa, para trazer para fora sempre novidade; e nada mais do que a materialidade do mundo que solicita nossos devaneios a renovação sem fim (WUNENBURGER 2016, p. 192).

Desse modo, a visão de mundo de Bachelard, que inaugura um processo fenomenológico de devaneio sobre a natureza como uma linha criadora dos pontos-vida iniciados por Roupnel. Contudo, há obviamente diferenças binárias na apropriação onírica do mundo por Bachelard, tanto que é possível situar uma especialização simbólica nos modos de representação e relação mais do que objetiva. Em A poética do devaneio é clássica a passagem que diz "eu sonho o mundo; logo, o mundo existe tal como eu o sonho." (BACHELARD 1996, p. 152)

Já em A poética do Espaço, Bachelard relembra a relação entre espaço e memória ao dizer que, "É pelo espaço, é no espaço que encontramos os belos fósseis de uma duração concretizados em longos estágios. $\mathrm{O}$ inconsciente estagia. As lembranças são imóveis e tanto mais sólidas o quanto mais bem espacializadas." (BACHELARD 1993, p. 203).

Logo, entendemos que a visão de mundo e espaço entre Roupnel e Bachelard entram numa correlação simétrica na medida em que

No mundo todo, cada ser e cada coisa tem tempo construído na medida das obras de sua consciência. Mais exigido pelas leis do matemática estelar, a vida requer a relatividade do tempo; e ele distribui o significado do termo para as proporções do espírito. (ROUPNEL 1927, p. 115).

Assim, entendemos que a consciência do sonho, da relatividade do tempo e da relação entre o micro e o macro 
se constituem no eixo da unidade do pensamento de ambos os pensadores.

\section{CONSIDERAÇÕES FINAIS}

A visão roupneliana é a de quem tinha vivido em uma cidade do vinho como um menino e estava familiarizado com a história local e o folclore. Roupnel quer dar voz a uma natureza que cria incessantemente, ao mesmo tempo, nessa relação filosófica sob a interpretação bachelardiana, alargamos nossos horizontes e demonstramos que é possível também, em certo sentido, falar sobre religião a partir de Bachelard. Tal constatação se dá pelo fato de que um panenteísmo enquanto religião filosófica se adequa perfeitamente a uma síntese de um darwinismo e um criacionismo mais espiritualista.

Há também que se observar que a tese espiritualista de Roupnel foi publicada antes do panenteísmo de Teilhard Chardin $^{6}$, que teria grande convergência com Roupnel. O panenteísmo que é incorretamente interpretado pela maioria das pessoas como o mesmo que o panteísmo. É fundamentalmente um tipo de monismo que reconhece a divindade em todas as coisas. Por isso,

O cego de nascença, que recupera sua vista por lavagem dos olhos nas águas da fonte de Siloë representa, para Roupnel, o ser livre feito

\footnotetext{
6 "Roupnel écrit "[qu'il] m'a été permis de prendre connaissance des manuscrits du Père Teilhard de Chardin. Cette haute pensée a exercé sur moi une influence dont on trouvera plus d'une fois le témoignage dans le présent ouvrage," Nouvelle Siloë, 19. Pierre Teilhard de Chardin, Le phénomène humain" (Roupnel apud Whalen, 2001, p. 96).
} 
para realizar o seu destino. Sua cosmologia é inspirada nas mônadas de Leibniz. Ele também acredita na redenção de ser. (PARINAUD 1996, p. 80).

Nesse sentido, haveria aí uma vertente diferente de investigação que fomentaria uma descontinuidade entre Bergson-Roupnel-Bachelard e possibilitaria um fundo mais antigo baseado em Leibniz, contudo esse seria o tema para uma futura pesquisa nesse âmbito. A iniciativa de resgatar Siloë em traduções para o português demonstra também que há uma relação provável entre a noção de ritmo francesa e a resgatada por Bachelard na figura luso-brasileira de Lúcio Pinheiro dos Santos.

Talvez seja de lá que o tempo a ser consumido dará vida ao sistema atômico de um universo, onde constantemente se alterna o ritmo do indeterminado e o indivíduo, o átomo e o universal. Porque esses ciclos e estas descontinuidades são a ordem da natureza. O espaço extra-atômico permanecerá para nós como se não existisse. E também é ilógico para construir o tamanho das coisas para desmaiar no sonho einteniano da matemática. (ROUPNEL 1927, p. 130 grifos nossos).

Contudo, é aí também que podemos vislumbrar uma diferença fundamental na apropriação bachelardiana da chamada descontinuidade como um aspecto rítmico. Nesse sentido, sua teoria de ontogênese é ligada a ideia do ritmo realmente por Bachelard, na medida em que ele assume a perspectiva negativa dessas noções a priori do tempo e espaço por um a posteriori atomista ou de uma miniatura caprichosa, por assim dizer.

O que dura no tempo não é o que perdura uniforme e regularmen- 
te. A equação bergsoniana da continuidade do tempo e da plenitude do ser é contestada por Bachelard, que se confessa fundamentalmente interessado em demonstrar que o ser, o movimento, o espaço e a durações são dialeticamente negados pelo nada, pelo repouso, pelo ponto e pelo instante. (SOUZA 1987, p. 77).

Por fim, Bachelard estabelece nessas intuições uma nova perspectiva de unidade do mundo, que é habito pela espacialidade da casa e pela individualidade do corpo.

Résumé: Cette recherche vise à soutenir l'idée, en hommage après le 60e anniversaire de la mort de Gaston Roupnel (1871-1946), qu'il y a une influence qui va au-delà de la notion de discontinuité et instantanée sur Bachelard (1884-1962). De cette façon, le tour de la philosophie de Bachelard à la critique littéraire et poétique une vision du monde imprègne entreprise par Roupnel de Siloë (travail très rare, souvent cité indirectement et non encore traduit en portugais). En ayant un accès direct au texte, il est clair qu'il y a donné un nouveau départ, une nouvelle ontogenèse de la vie à l'idée de la rêverie de l'espace dans une perspective qui combine la durée et le temps, l'espace et le temps. Nous avons l'intention de dévoiler l'influence de roupneliana chez Bachelard sur l'intuition du moment, afin de démontrer l'hypothèse qu'il était de Siloë qui ouvre l'espace à la rêverie bachelardienne.

Mots-clés: Géopoïétique; l'espace; temps; l'énergie.

\section{REFERÊNCIAS}

\section{BACHELARD, Gaston. A poética do Espaço. Tradução de Antonio de Pádua Danesi. São Paulo: Martins Fontes, 1993.}

A poética do devaneio. Tradução Antônio de Pádua Danesi. São Paulo : Martins Fontes, 1996.

. O mundo como capricho e miniatura. IN: Estudos. Trad. Estela Santos Abreu. Rio de Janeiro: Contraponto, 
2008.

BONTEMPS, Vincent. Bachelard. Paris: Le belles lettres, 2010.

BOUVET, Rachel. Como habitar o mundo de maneira geopoética. Revista Interfaces, UFPel. v. 12, n. 1, 2012

GAGEY, Jacques. Gaston Bachelard ou la conversion à l'imaginaire.

Paris:

Marcel

Rivière, 1969.

MOVSCHOWITZ, Raquel. A piscina de Siloé. Movschowitz, Raquel. A piscina de Siloé. In: BUlCÃO \& CARVALHO. Revista Filosófica Brasileira. Rio de Janeiro: UFRJ, 1993.

PARINAUD, Andre. Gaston Bachelard. Paris: Flamarion, 1996.

ROUPNEL, Gaston. Siloë. Paris: Libraire Stock, 1927.

SOUZA, R. M. . Epistemologia e Hermenêutica em Bachelard. Tempo Brasileiro, Rio de Janeiro, v. 90, p. 47-93, 1987.

WHALEN, Philip. "La mise en lumière des travaux de Gaston Roupnel (1871-1946) en vue de la "Préface" inédite de l'Histoire de la campagne française. Ruralia 8 (2001) : 89-101.

WHITE, Kenneth. Elements of Geopoetics, Edinburgh Review, 88, 1992. p. 163-181.

WUNENBURGER, Jean-Jacques. L'imagination géopoïetique. Paris: Mimesis, 2016. 